\title{
Anemia hemolítica imunomediada não regenerativa em um cão
}

\author{
Nonregenerative immune-mediated hemolytic anemia in a dog \\ Leonardo Pinto Brandão ${ }^{1}$ Júlia Habu Ikesaki² ${ }^{2}$ Samantha Ive Miyashiro ${ }^{3}$ \\ Maria Luisa Franchini ${ }^{2}$ Mitika Kuribayashi Hagiwara ${ }^{4}$
}

\section{- RELATO DE CASO -}

\section{RESUMO}

Quadros hemolíticos não eritrorregenerativos são descritos em cães e podem ser decorrentes de doença medular primária, bem como, da destruição dos precursores eritróides medulares por imunoglobulinas. Um cão macho, de três anos de idade, sem raça definida, foi atendido no Hospital Veterinário da Faculdade de Medicina Veterinária e Zootecnia da Universidade de São Paulo apresentando sinais de anemia hemolítica aguda arregenerativa. Após a instituição de terapia imunossupressora (prednisona), houve remissão da hemólise sem, no entanto, sinais de eritrorregeneração. No décimo dia de tratamento, o mielograma demonstrou discreta hipoplasia e displasia eritróide, descartando a possibilidade de aplasia medular. Associou-se ciclofosfamida e azatioprina ao tratamento, tendo havido resposta eritrorregenerativa e recuperação dos valores hematológicos. A ocorrência deste caso de anemia hemolítica não eritrorregenerativa deve servir como alerta para a ocorrência desta condição mórbida, como também, da importância da utilização do mielograma como método auxiliar no diagnóstico de anemias arregenerativas.

Palavras-chave: anemia, hemólise, cães, eritrorregeneração, imunossupressão.

\section{ABSTRACT}

Nonregenerative forms of immune-mediated hemolytic anemia has been describe in dogs and are attributed to bone marrow diseases or immune-mediated destruction of erythroid progenitors. A 3-year-old, male mongrel dog was received at the Veterinary Hospital of the Faculdade of Medicina Veterinária e Zootecnia da Universidade de São Paulo (USP), Brazil showing signs of acute hemolytic anemia without erythroregeneration. After immunosuppressive therapy (prednisone) the hemolysis was suppressed but the dog didn't show hematologic signs of erythroid response. On the $10^{\text {th }}$ day after treatment a bone marrow aspiration was performed and signs of hypoplasia and mild erythroid cell dysplasia were the main features observed, which could exclude the suspicious of marrow aplasia. After the addiction of cyclophosphamide and azathioprine to the treatment, erythroid response could be observed. This report of a nonregenerative immune-mediated anemia in a dog is an alert for the existence of this disease and shows the strong indication to perform a bone marrow aspiration to diagnose the nonregenerative forms of anemia.

Key words: anemia, hemolysis, dogs, erythroregeneration, immunosupression.

\section{INTRODUÇÃO}

A anemia hemolítica imunomediada (AHIM) é definida como uma redução do número de eritrócitos em decorrência da destruição por imunoglobulinas ou pelo sistema complemento - hemólise intravascular -

${ }^{1}$ Pós-graduando do Departamento de Clínica Médica da Faculdade de Medicina Veterinária e Zootecnia da Universidade de São Paulo - R. Paulo Ribeiro da Luz, 170 ap. 21, 05590-140, Butantã - São Paulo-SP. E-mail: leobrandao@yahoo.com. Autor para correspondência.

${ }^{2}$ Médicos Veterinários contratados do Departamento de Clínica Médica da Faculdade de Medicina Veterinária e Zootecnia da Universidade de São Paulo.

${ }^{3}$ Médico Veterinário responsável pelo Laboratório de Análises Clínicas da Faculdade de Medicina Veterinária das Faculdades Metropolitanas Unidas de São Paulo.

${ }^{4}$ Professor Titular do Departamento de Clínica Médica da Faculdade de Medicina Veterinária e Zootecnia da Universidade de São Paulo. 
ou ainda, pela remoção promovida pelo sistema monocítico fagocitário - hemólise extravascular (MILLER, 2000). A AHIM é reconhecida como causa freqüente do desenvolvimento de quadros anêmicos agudos em cães, podendo ter diferentes manifestações clínicas, responsivas ou não à terapia imunossupressiva única com corticosteróides, algumas vezes evoluindo desfavoravelmente, podendo levar ao óbito (MILLER, 1997a; HARKIN et al., 1998).

Dentre as alterações laboratoriais observadas, a ocorrência de anemia moderada a intensa - freqüentemente apresentando hematócrito inferior a $15 \%$ - de características regenerativas (macrocitose, policromasia, reticulocitose e eritroblastose), é considerada como patognomônica desta afecção; no entanto, casos de AHIM sem sinais de eritrorregeneração são freqüientes - em $50 \%$ dos casos -, devendo-se ater cuidadosamente à sua ocorrência (MILLER, 2000; STOKOL et al., 2000).

As anemias não regenerativas podem ser decorrentes de uma produção eritróide insuficiente associada a doenças medulares idiopáticas, hipoplasia ou aplasia medular causada por exposição a micotoxinas, medicamentos mielotóxicos (cloranfenicol, sulfas, etc), e a deficiência de eritropoetina nos casos de insuficiência renal crônica (DAY, 1998; ROGERS, 2000). Quadros hemolíticos não eritrorregenerativos foram observados em cães com crises agudas nos quais ainda não houvera tempo para a liberação de hemácias jovens na circulação (o que pode levar até 3 dias), casos de doença medular primária com conseqüente supressão da mielopoese, doença medular infiltrativa, deficiência nutricional associada (hipoferremia) ou destruição imune dos precursores eritróides na medula óssea (STOKOL et al., 2000). A aplasia eritróide adquirida é decorrente de uma doença imunomediada em que há destruição de eritrócitos circulantes e formação de anticorpos contra os precursores eritróides na medula óssea. Essa doença é considerada rara e pode estar associada a lesões pelo vírus da parvovirose canina (TVEDTEN \& WEISS, 1999).

Estados hemolíticos associados à ausência de eritrorregeneração caracterizam-se como um desafio para o diagnóstico clínico, uma vez que a resposta eritróide compensatória ao quadro anêmico agudo, decorrente da hemólise, é esperada e auxilia a confirmar o diagnóstico da doença. O objetivo deste relato de caso é alertar para a ocorrência de estados hemolíticos arregenerativos na espécie canina.

\section{RELATO DO CASO}

Em outubro de 2000, um cão, macho, sem raça definida, de 3 anos de idade, foi atendido no Hospital Veterinário da Faculdade de Medicina Veterinária e Zootecnia da USP com histórico de colúria, prostração e febre há 3 dias, tendo recebido transfusão sangüínea e aplicação de dipropionato de imidocarb.

Ao exame físico, o animal apresentava-se prostrado, com membranas mucosas perláceas e ictéricas, com hepato e esplenomegalia acentuadas, hipertérmico $\left(39,7^{\circ} \mathrm{C}\right)$ e moderadamente desidratado. Solicitou-se hemograma, contagem de plaquetas, urinálise, função renal e hepática, tendo sido diagnosticado anemia arregenerativa com presença de esferócitos. Suspeitou-se de quadro hemolítico agudo em decorrência da intensa anemia, bilirrubinúria e icterícia, bem como, presença de esferócitos no esfregaço do sangue periférico. O tratamento instituído foi a prednisona na dose de $2 \mathrm{mg} / \mathrm{kg}$ a cada 12 horas. Os resultados dos exames bioquímicos não demonstraram alterações na função renal ou hepática e o exame ultra-sonográfico de abdome não revelou alterações estruturais no parênquima hepático ou renal, descartando-se doença destes órgãos (Tabela 1).

O acompanhamento diário subseqüente do animal demonstrou uma reticulocitose insuficiente para a recuperação dos valores eritróides, bem como, hemácias normocíticas e normocrômicas características de processos anêmicos não regenerativos, havendo ainda queda progressiva do hematócrito e a manutenção da trombocitopenia durante o período de acompanhamento. No décimo dia, foi realizado mielograma do material medular obtido por punção aspirativa da crista ilíaca, tendo sido demonstrado hipoplasia celular discreta, caracterizada por uma hipoplasia eritróide (relação mielóide/eritróide $=2,2$ ), bem como, uma assincronia de maturação núcleo/ citoplasma da série eritróide (diseritropoese). Não foram observadas outras alterações morfológicas ou de maturação da série mielóide e megacariocítica. Neste mesmo dia, as hemácias do animal foram submetidas ao teste direto de Coombs para a detecção de imunoglobulinas aderidas à membrana eritrocitária e o resultado foi negativo.

Adicionou-se ao tratamento azatioprina (Imuran $^{\circledR}$ ) na dose de $2 \mathrm{mg} / \mathrm{kg}$ a cada 24 horas e ciclofosfamida $\left(\mathrm{Genuxal}^{\circledR}\right) 50 \mathrm{mg} / \mathrm{m}^{2}$ a cada 48 horas (MILLER, 2000). Os exames subseqüentes demonstraram resposta medular com reticulocitose e eritrorregeneração havendo correção gradativa dos 
Tabela 1 - Resultados dos exames laboratoriais do cão com anemia hemolítica imunomediada não eritrorregenerativa, realizados no primeiro dia de atendimento - São Paulo, 2003

\begin{tabular}{|c|c|c|}
\hline & DIA 1 & $\begin{array}{l}\text { Valores de } \\
\text { referência* }\end{array}$ \\
\hline Hemácias $\left(10^{6} / \mathrm{mm}^{3}\right)$ & 2,87 & $6,15-8,7$ \\
\hline $\mathrm{Ht}(\%)$ & 19 & $43,3-59,3$ \\
\hline $\mathrm{Hg}(\mathrm{g} / \mathrm{dL})$ & 6,8 & $14,1-20,0$ \\
\hline VCM (fL) & 66 & $63,0-77,1$ \\
\hline $\mathrm{HCM}(\mathrm{pg})$ & 24,0 & $21,1-24,8$ \\
\hline $\mathrm{CHCM}(\%)$ & 36,0 & $29,9-35,6$ \\
\hline Leucócitos $\left(/ \mathrm{mm}^{3}\right)$ & 8.000 & $6.000-16.000$ \\
\hline Neutrófilos totais & $75 \%(6.800)$ & $3.230-10.850$ \\
\hline Neutrófilos metamielócitos & $0 \%$ & - \\
\hline Neutrófilos bastonetes & $0 \%$ & - \\
\hline Neutrófilos segmentados & $85 \%(6.800)$ & \\
\hline Linfócitos & $8 \%(640)$ & $530-3.440$ \\
\hline Monócitos & $3 \%(240)$ & $0-430$ \\
\hline Basófilos & $0 \%$ & $1-540$ \\
\hline Eosinófilos & $4 \%(320)$ & $0-1.820$ \\
\hline Plaquetas $\left(/ \mathrm{mm}^{3}\right)$ & 85.000 & $164.000-510.000$ \\
\hline Reticulócitos corrigidos & $0,5 \%$ & $<1 \%$ \\
\hline Esferócitos & ++ & - \\
\hline $\mathrm{FA}(\mathrm{UI} / \mathrm{L})$ & 80 & $0-90$ \\
\hline ALT (UI/L) & 25 & $10-94$ \\
\hline Bilirrubina (mg/dL) total & 2,5 & $0,1-0,6$ \\
\hline Direta & 0,8 & \\
\hline Indireta & 1,7 & \\
\hline Albumina (g/dL) & 3,5 & $3,2-4,7$ \\
\hline Proteína total (g/dL) & 7,5 & $5,3-7,6$ \\
\hline \multicolumn{3}{|l|}{ Urinálise } \\
\hline Densidade & 1,032 & $1,025-1,045$ \\
\hline $\mathrm{pH}$ & 7,5 & dependente da dieta \\
\hline Coloração & Âmbar & \\
\hline Odor & Sui generis & \\
\hline Cristais & Ausentes & \\
\hline Cilindros & Hialinos & \\
\hline Células & raros & \\
\hline Bactérias & Ausentes & \\
\hline Proteína & Raras & \\
\hline Glicose & + & - \\
\hline Corpos cetônicos & - & - \\
\hline Urobilinogênio & - & \\
\hline Pigmentos biliares & +++ & \\
\hline \multirow[t]{2}{*}{ Hemoglobina } & +++ & \\
\hline & ++ & \\
\hline \multicolumn{3}{|c|}{ * TVEDTEN \& WEISS, (1999) } \\
\hline
\end{tabular}

valores eritróides e do número de plaquetas circulantes (Figura 1). A partir do 50ํ dia, iniciou-se redução gradativa da terapia imunossupressora com a suspensão da ciclofosfamida, redução gradativa da prednisona e da azatioprina até que, no $75^{\circ}$ dia, o animal recebeu alta.

\section{DISCUSSÃO}

A anemia hemolítica imunomediada sem características eritrorregenerativas é uma doença reconhecida em cães e parece ser decorrente da destruição dos precursores eritróides medulares por imunoglobulinas (JONAS et al., 1987; COTTER, 2000; STOKOL et al., 2000), podendo acometer cerca de 50\% dos cães com distúrbios hemolíticos (MILLER, 2000). As alterações laboratoriais observadas (queda aguda do hematócrito, bilirrubinúria, hemoglobinúria e esferocitose) eram compatíveis com anemia hemolítica, no entanto, a ausência de sinais de eritrorregeneração (macrocitose, policromasia, reticulocitose e normoblastemia) à análise citológica do esfregaço sangüíneo dificultou o diagnóstico. $\mathrm{O}$ aumento dos órgãos do sistema monocítico fagocitário era indicativo do incremento da atividade fagocítica envolvida na retirada de hemácias circulantes - hemólise extravascular -, como descrito por DAY (1999). A terapia imunossupressora à base de prednisona, associada a outros medicamentos citotóxicos, como a azatioprina e a ciclofosfamida, é recomendada por diversos autores (COHN, 1997; BURGESS et al., 2000; GRUNDY \& BARTON, 2001) e parece aumentar a oportunidade de sucesso no tratamento por coibir a provável ação de anticorpos direcionados contra os precursores eritróides medulares, revertendo o quadro anêmico.

O resultado negativo do teste direto de Coombs não exclui o diagnóstico de anemia hemolítica imunomediada, visto que apenas $57 \%$ dos animais demonstram positividade a ele (STOKOL et al., 2000), e ainda, a possível ação da prednisona administrada ao paciente, coibindo a formação de anticorpos antieritrocitários (REIMER et al., 1999). A trombocitopenia associada ao processo é achado comum - 70\% dos casos - e pode ser decorrente da destruição imunomediada das plaquetas, ou ainda, secundária a processos de consumo como a septicemia ou a coagulação intravascular disseminada (MILLER, 2000).

A análise do mielograma permitiu descartar a existência de aplasia medular, comumente associada em nosso meio como decorrente da infecção por riquétsias (ANDEREG \& PASSOS, 1999), e ainda, avaliar os precursores eritróides na medula óssea, os quais se mostraram discretamente reduzidos em número. Descartou-se a possibilidade de mielodisplasia em decorrência da resposta à terapia imunossupressora instituída, bem como de que alterações displásicas brandas podem ser encontradas em animais com anemia hemolítica arregenerativa (STOKOL et al., 2000). 


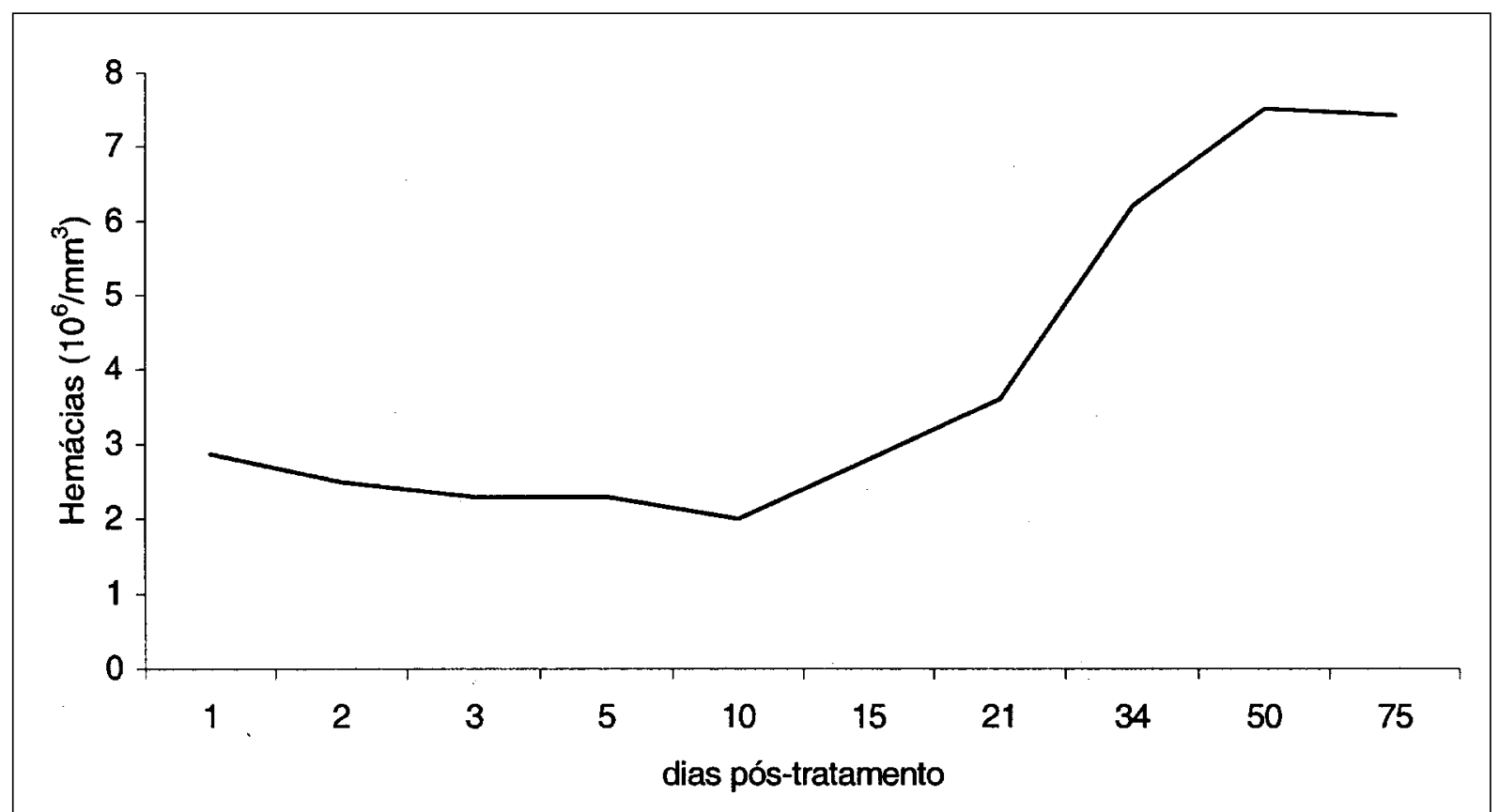

Figura 1 - Hematimetria durante o período de tratamento do cão com anemia hemolítica imunomediada não eritrorregenerativa - São Paulo, 2003.

A resposta eritrorregenerativa observada após a associação de ciclofosfamida e azatioprina, no décimo dia de tratamento, parece ter sido fundamental para bloqueio da ação de anticorpos produzidos contra os precursores eritróides medulares, como suspeitado, confirmando o diagnóstico de doença hemolítica imunomediada, mesmo na ausência de eritrorregeneração (MILLER, 1997b; MILLER, 2000). A combinação de corticosteróides e outros medicamentos imunossupressores pode aumentar a oportunidade de recuperação dos pacientes, e ainda, prolongar o tempo de sobrevivência quando comparado a animais não tratados ou que receberam como tratamento apenas um agente imunossupressor (REIMER et al., 1999; MACKIN, 2000).

\section{CONCLUSÃO}

A ocorrência deste caso de anemia hemolítica não eritrorregenerativa deve servir tanto como alerta para a ocorrência desta condição mórbida, como também para a importância de utilizar-se o mielograma como meio auxiliar no diagnóstico de anemias arregenerativas.

\section{REFERÊNCIAS BIBLIOGRÁFICAS}

ANDEREG, P.I.; PASSOS, L.M.F. Erliquiose canina - Revisão. Clínica Veterinária, n.19, p.31-39, 1999.
BURGESS, K. et al. Treatment of immune-mediated hemolytic anemia in $\operatorname{dog} s$ with cyclophosphamide. Journal of Veterinary Internal Medicine, v.14, p.456-462, 2000.

COHN, L.A. Glucocorticosteroids as immunosuppressive agents. Seminars in Veterinary Medicine and Surgery (Small Animal), v.12, n.3, p.150-156, 1997.

COTTER, S.M. Non-regenerative anemia. In: ETTINGER, S.J.; FELDMAN. E.C. Textbook of veterinary internal medicine. 5.ed. Philadelphia : Saunders, 2000. Cap.178, p.1804-1816.

DAY, M.J. Immune-mediated hemolytic anemia. Veterinary Quarterly, v.20, s39-s40, 1998.

DAY, M.J. Antigen specificity in canine autoimmune haemolytic anaemia. Veterinary Immunology and Immunopathology, v.69, p.215-224, 1999.

GRUNDY, S.A.; BARTON, C. Influence of drug treatment on survival of dogs with immune-mediated hemolytic anemia: 88 cases (1989-1999). Journal of the American Veterinary Medical Association, v.218, n.4, p.543-546, 2001.

HARKIN, K.R.; BRASELTON, W.E.; TVEDTEN, H. Pseudohypophosphatemia in two dogs with immune-mediated hemolytic anemia. Journal of Veterinary Internal Medicine, v.12, p.178-181, 1998.

JONAS, L.D.; THRALL, M.A; WEISER, M.G. Nonregenerative form of immune-mediated hemolytic anemia in dogs. Journal of the American Animal Hospital Association, v.23, p.201-204, 1987.

MACKIN, A. Advances in the treatment of immune-mediated 
blood disorders. In: AMERICAN CONGRESS OF VETERINARY INTERNAL MEDICINE, 18., 2000. Proceedings... Seattle : n.i., 2000. p.465.

MILLER, E. Immunosuppression - an overview. Seminars in Veterinary Medicine and Surgery (Small animal) v.12, n.3, p.144-149, 1997a.

MILLER, E. The use of cytotoxic agents in the treatment of immune-mediated diseases of dogs and cats. Seminars in Veterinary Medicine and Surgery (Small animal), v.12, n.3, p.157-160, 1997b.

MILLER, E. CVT up date: diagnosis and treatment of immunemediated hemolytic anemia. In: BONAGURA, J.D. (Ed.) Kirk's current veterinary therapy XIII - Small animal practice. Philadelphia : Saunders, 2000. p.427-434.

REIMER, M.E.; TROY, G.C.; WARNICK, L.D. Immune- mediated hemolytic anemia: 70 cases $(1988$ - 1996). Journal of the American Animal Hospital Association, v. 35 p.384-395, 1999.

ROGERS, K.S. Anemia. In: ETTINGER, S.J.; FELDMAN E.C. Textbook of veterinary internal medicine. 5.ed. Philadelphia : Saunders, 2000. p.198-203.

STOKOL, T.; BLUE, J.T.; FRENCH, T.W. Idiopathic pure red cell aplasia and nonregenerative immune-mediated anemia in dogs: 43 cases $(1988$ - 1999). Journal of the American Veterinary Medical Association, v. 216, n.9, p.1429-1436, 2000 .

TVEDTEN, H.; WEISS, D. Erythrocyte disorders. In: WILLARD, M.D.; TVEDTEN, H.; TURNWALD, G.H. Small animal clinical diagnosis by laboratory methods. 3.ed. Philadelphia : Saunders, 1999. Cap.3, p.31-52. 